\title{
ANÁLISIS DE RIESGO EXISTENCIAL Y EL FUTURO DE LA EMPLEABILIDAD
}

\section{Existential risk analysis and the future of employability}

\author{
Sonia Lidia Romero Vela \\ Universidad Femenina Sagrado Corazón.soniaromerov@unife.edu.pe \\ https://orcid/0000-0002-9403410X
}

\begin{abstract}
RESUMEN
La humanidad se encuentra en peligro de extinción, el mundo vive una guerra contra un enemigo invisible en este siglo XXI, la Pandemia Covid-19, la cual no sólo pone en riesgo la vida de las personas, sino que nos muestra el lado deshumano, a la que nos ha llevado esta política neoliberal tales como: el abandono de la salud, la educación, la inseguridad y otros problemas más. Frente a ello la presente investigación tiene como objetivo principal analizar el riesgo existencial y la empleabilidad. Para dicho fin se revisó bibliografía, documentos, decretos, normas y leyes, luego se determinó el potencial riesgo existencial de la inteligencia artificial y la bionanotecnologìa. Se debe reflexionar desde una política pública que considere en riego existencial el futuro de la empleabilidad frente al contexto covid -19 y pos-pandemia.
\end{abstract}

\section{Palabras clave:}

Riesgo existencial, políticas públicas, empleabilidad

\begin{abstract}
Humanity is in danger of extinction, the world lives a war against an invisible enemy in the 21 st century, the Covid -19 pandemic, which not only puts people's lives at risk, but also shows us the inhuman side to which the neoliberal policy has led us such as: the abandonment of health, education, and security. The main objective of this research is to analyze existential risk and employability. Bibliographic review was carried out, as well as the analysis of documents, decrees, norms and laws. Artificial intelligence, biotechnology and the pandemic itself were identified as potential existential risks for the future work. It is necessary to reflect from a public policy that considers the future of employability at existential risk facing the covid-19 and post-pandemic context.
\end{abstract}

\section{Keywords:}

Existential risk, public policies, employability 


\section{INTRODUCCIÓN}

Frente a tiempos críticos e individualistas y con fines económicos, utilitaristas y políticos más que sociales y de interés público, nos enfrentamos a una crisis humanitaria y de riesgo existencial del hombre junto a la naturaleza, donde la antropología, sociología, filosofía y otras disciplinas de las ciencias sociales y humanas han sido dejadas de lado por la economía, la ciencia, la inteligencia artificial y otras ciencias aplicadas y tecnológicas que son utilizados en las sociedades actuales (Romero, 2019). La modernización ha traído desarrollo y avance tanto en tecnología y ciencia, también velocidad y hasta radicalidad, observamos una nueva moral política. Las decisiones técnicas y económicas que se debaten en público también pasan por transformaciones. Beck (2008) expresa que esta tecnología trae una involución en el ámbito social, el avance no es homogéneo en lo económico, tecnológico, político, cultural y social las brechas son cada vez más grandes.

El riesgo existencial es mundial producido por los avances de la tecnología. Inglaterra preocupada por la temática del riesgo existencia reconoce muchos privilegios, desarrollo y avances de la tecnología, pero también, el mal uso puede ocasionar grandes riesgos, como son: la Inteligencia artificial, el cambio climático, biotecnología y nanotecnología que pueden tener el riesgo potencial de extinguir nuestra especie. Esta preocupación ha llevado a un equipo multidisciplinario entre ellos un filósofo, un científico y un ingeniero de software, para crear el Centro de Estudio de Riesgos Existenciales (CSER) liderado por el filósofo Price quién anticipó que la inteligencia artificial abriría una caja de pandora y que si fallamos podemos obtener resultados desastrosos por eso debemos considerar los riesgos de la tecnología potencialmente peligrosos (Zamorano, 2012). En Latinoamérica, países de Centro América vienen atravesando problemas de hambre y pobreza incluso antes de la Pandemia, al respecto la Organización de las Naciones Unidas para la Alimentación (FAO, 2017) refirió que la pandemia de coronavirus incrementará el hambre y la pobreza en los países de América Latina y el Caribe. Ya podemos evidenciarlo en países como Brasil que el producto bruto interno (PIB) se contrajo en un 4,5\% frente a una previsión anterior de un declive de 1,7\%., así como Guyana, Cuba y otros. Asimismo, encontramos el reporte de Comisión Económica para América Latina y el Caribe (CEPAL, 2020) que señala la existencia de un estado de inseguridad alimenticia en el mundo, a pesar del bono por alimentos que han creado, vemos que no ha llegado a todos.

Antes de la pandemia fuimos arrasados por el fenómeno de la corrupción y esto nos refleja el retroceso en nuestro sistema político, inclusive las brechas siguen siendo abismales. La población peruana está en riesgo, no sólo por la pandemia, ahora hay que sumarle el despido laboral (suspensión perfecta), el problema éticomoral (incumplimiento de las normas), los bonos humanitarios y canastas que no han llegado a todos los rincones del país, (producto de la corrupción), la informalidad, la desprotección del Estado en algunos sectores (Salud y Educación). El sistema neoliberal al cual estamos inmersos gracias al Consenso de Washington no nos permite avanzar en políticas sociales (Martínez y Reyes, 2012). Ante ello surge la siguiente interrogante: ¿Por qué es importante reflexionar sobre la empleabilidad como un riesgo existencial?, ¿Por qué se deben generar 
políticas públicas y pensar en el futuro de la empleabilidad a partir de los avances de la inteligencia artificial? Gómez (2019) señaló que la inteligencia artificial es una herramienta muy eficiente, productiva y capaz que puede ayudar a evitar tareas repetitivas, por ejemplo, puede reconocer patrones que desde la seguridad permitirá detectar irregularidades; por otro lado, la inteligencia artificial (en adelante, IA) puede contrarrestar la escasez de profesionales, ya que la tecnología se encargaría de las tareas rutinarias y los profesionales de tareas que harán crecer el negocio. Para lo cual se plantea analizar la importancia del riesgo existencial en el futuro de la empleabilidad para evitar despidos masivos y el uso indebido y antiético que se pueda generar en los empresarios y políticos tanto del sector público y privado frente al avance de la tecnología y la IA.

\section{Riesgo existencial, empleabilidad y políticas públicas}

Se ha considerado definir que el riesgo existencial ( $\mathrm{RE}$, en adelante), según Bostrom, es un potencial degradador del bienestar de la mayoría de la humanidad. El reclasificado según los escenarios: las explosiones, desastres brutales (accidentales o deliberadas) guerras nucleares y el uso agresivo, en la nanotecnología y los impactos cósmicos. Sumado a estos riesgos el agotamiento de los recursos, el calentamiento global y el riesgo mismo por acciones humanas. (Brosi, Dodds, E Passeron 2019).

La empleabilidad es la principal muestra de una formación profesional de alta calidad y de políticas públicas bien definidas. La empleabilidad es también una variedad de calificaciones que se usan para conservar un puesto de trabajo. (Organización Internacional del Trabajo, 2002). Podemos señalar, a la luz de las definiciones expuestas, el futuro de la empleabilidad está en riesgo existencial por lo cual es necesaria una política pública. Según Engels (1876; citado en Berdichewsky, 2002) el trabajo es la condición básica y primordial de todo humano y podemos decir inclusive que el trabajo ha creado al propio hombre, el trabajo es un papel imprescindible en el desarrollo del hombre, sin embargo, observamos que el trabajo también ha ido evolucionando. Podemos inferir que el trabajo es y seguirá siendo el Quid de la existencia, por otro lado, sabemos que Dios creo al hombre producto de su trabajo, es a partir de allí que debemos considerar desde una concepción positiva, el Dios bíblico del Génesis creó al hombre para que sea fructífero y multiplique la tierra y con ello le otorgue el mandato divino del trabajo (García, 2019).

La Inteligencia Artificial, subcategoría del REcon sus orígenes en la programación electrónica, definida por la RAE (2018) como "potencia Intelectual, facultad de conocer, de entender o comprender". Se podría decir lo mismo pero aplicado a las máquinas. Marvin Minsky señaló que la IA "es la ciencia de construir máquinas para que hagan cosas, si las hicieran los humanos, requerirían inteligencia". Se aplica a diferentes áreas: tratamiento de lenguajes naturales (sistema operativo, base de datos, etc.), sistemas expertos, robótica, problemas de percepción: visión, habla y aprendizaje. La automatización del trabajo remoto ha llevado, en estos tiempos, a remplazar la mano de obra humana en diferentes espacios así en instituciones privadas y públicas, al respecto se ha considerado urgente tomar medidas de regulación para frenar los futuros ceses masivos. 


\section{Material y métodos}

El Riesgo Existencial se basa en estudios cualitativos utilizando categorías y políticas públicas, que "nos permite interpretar el mundo desde la subjetividad, principios metodológicos de cómo interpretar el mundo desde la interacción de actores sociales" (Bernal, 2016, p.74). Los actores de la investigación son el gobierno, los ciudadanos y la relación entre ellos, como dice Bonilla y Rodríguez (2005), la realidad social es el resultado de un proceso interactivo en el que participan los miembros de un grupo para negociar y renegociar la construcción de esa realidad. El Perú fue escenario de estudio en la investigación cualitativa, como dice Galeano (2004) el muestreo es progresivo porque está expuesto a las dinámicas que se deriva de los hallazgos de la investigación, es secuencial, conducido y no se establece al azar ni con fórmulas matemáticas.

\section{Desarrollo}

Al analizar la importancia el RE como un potencial peligro para el futuro de la empleabilidad se han considerado los siguientes aspectos:

Las políticas públicas sobre todo en el campo social, se llegó incluso a juntar con la ciencia política como un conjunto de disciplinas que se direccionan en la solución de problemas. Políticas Públicas según Subirats (2008) como una serie de decisiones o de acciones, intencionalmente coherentes, tomadas por diferentes actores, públicos y a veces no públicos -cuyos recursos, nexos institucionales e intereses varíana fin de resolver de manera puntual un problema políticamente definido como colectivo.
La teoría crítica de la sociedad del riesgo mundial (Arana, 2005) investigó sobre los nuevos enfoques en estudios de Ciencia, Tecnología y Sociedad como un posible fundamento y alternativa para la educación científica y tecnológica en la educación superior. Por otro lado, encontramos a Bostrom (2014) quien refirió que todos estos fenómenos son provocados y ocasionados por el hombre y su ambición de perfección (Transhumnaismo) que están llevándonos a la destrucción. En esa línea encontramos en Beck (2007) que señaló a la Sociedad del riesgo, ya que la genética, la nanotecnología y la robótica han abierto una nueva caja de pandora, por eso es importante insistir públicamente la buena intención y beneficios sociales de los posibles riesgos. El autor muestra su preocupación por la lógica del reparto de la riqueza y también, como las sustancias nocivas en las ciencias naturales que pondrán en situación de riesgo a sociedades enteras. Por otro lado, en la teoría política del conocimiento en la sociedad del riesgo como los errores, fraudes, defectos la conciencia pública dice: "Para la crítica de la ciencia por la conciencia civilizadora, lo contrario pasa porque, en último término, uno mismo tiene que remitirse a aquello contra lo que se argumenta. (...) Más pronto que tarde uno choca con la dura ley que establece que mientras los riesgos no sean reconocidos científicamente estos no existen." (p.80) Los problemas planteados no serán resueltos desde la parte jurídica, tecnológica ni social incluso ni tratados ni resarcidos, sólo lo puede hacer la ciencia.

La tecnología y la ciencia han generado alternativas efectivas que permiten el mejor desarrollo y avance para algunas empresas, organizaciones e instituciones. La robótica hoy en 
día es usada en algunas universidades peruanas privadas, vienen utilizando un chat (robot) llamado Arturito como son el caso de los bancos BCP, Scotiabank (Chatbot) y universidades como UPC, Cayetano Heredia y otros según el Diario Gestión (2019). Por otro lado, podemos decir que IA está poniendo en riesgo la empleabilidad en el Perú mucho más en este tiempo de pandemia donde muchas empresas se han amparado a la "suspensión perfecta". El posible allí el reemplazo humano por la robótica en la industria, empresas y pronto en las universidades. En Japón han creado un robot que ayuda en el aprendizaje del idioma inglés, facilita hacer las tareas y ensayar la pronunciación de dicho idioma ¿cuál será el futuro de los docentes si son reemplazados por robot?, de hecho, han invertido 227.000 dólares por el costo de 500 robots, tal como nos informan Escolano y Cazorla (2003).

La Bionanotecnología y el futuro de la sociedad tiene una gran atención e inversión de desarrollo. Esta nace como fruto de la fusión de la biotecnología y la nanotecnología. Se habla de Biotecnología, sobre todo por el desarrollo y avance en la ingeniería genética, ya que despierta interés público, institucional y hasta académico de acuerdo con Lujàn y Moreno (2014) quienes centraron la Biotecnología en el campo de la humanidad con dos diagnósticos: el contexto clínico y no clínico, y segundo, la terapia genética que consiste en evaluar las células somáticas y las células germinales. Se subdivide en dos: redes neuronales y agentes inteligentes, estos han invadido nuestras casas y tiene toda la información sobre nosotros, quizá más que nosotros mismos. Ejemplo de ello podemos ver los microchips avanzados, como los programas que acortan las respuestas con un impulso muscular de un brazo biónico que puede identificar en el movimiento. La robótica está dando soluciones en base a células madre para generar brazos, pies, ojos y materia prima realista, así como la funcionalidad de un brazo amputado, de esto nos informa Avalos, Haza, y Morales (2016).

\section{El sentido antropológico}

Es el principal causante del RE es el hombre y su ambición de perfección (transhumanismo) que están llevándonos a la destrucción (Bostrom, 2019). Este deseo está conduciendo a la extinción de la raza humana y de toda naturaleza. Èl es el único responsable porque no sólo está degenerando la naturaleza, sino a él mismo y esto trae problemas como: crisis, vacíos existenciales y hasta la pérdida del sentido de la vida causado por el individualismo, el analfabetismo axiológico y la "ética sin moral". Al respecto, Cortina (2008) señaló que se debe crear una ética civil articulada a los derechos humanos donde la doble moral no sea la regla sino la excepción. En esa misma línea Rees (2017) afirmó que se va a modificar a los seres humanos mediante ciborgs y técnicas de edición de genes hasta rediseñar a los mismos seres humanos, pero afirma la ineficiencia al ser regulados, igual se desarrollará en el futuro. Se mostraba preocupado porque no es como hace cuarenta años, cuando los primeros científicos en relación con el ADN se reunían para decidir las directrices al respecto sin injerencias de otros ámbitos. Sin embargo, hoy en día la empresa es internacional, con fuertes presiones comerciales, cada vez el uso de estas nuevas tecnologías se hace menos controlables, así como los medicamentos en la industria farmacéutica. (Hulmes, 2017). 
Al intentar responder ¿Por qué es importante reflexionar sobre la empleabilidad como un riesgo existencial?, esto nos lleva a pensar que no sólo debemos preocuparnos por los huaicos, la erupción de un volcán, terremotos y otros desastres naturales; sino que también debemos preocupar por los desastres que está ocasionando el propio hombre en este caso el avance descontrolado de la IA poniendo en "jaque mate" a muchos trabajadores de distintas empresas. En nuestro país la emergencia sanitaria obligó a tomar decisiones políticas que llevaron a los ceses colectivos o "suspensión perfecta" (Gestión, 2020) en su titular citó a más de 200,000 trabajadores afectados, frente a ello la ministra de trabajo reaccionó y señaló que se sancionaría por ponerse en riesgo la seguridad y la salud en un estado de emergencia a pesar de la contención del estado con apoyo de financiamiento de las Mypes a través del Fondo de Apoyo Empresarial (FAE).

Es necesaria la gestión de los recursos naturales y recursos humanos de una forma cuidadosa. Racionalmente consideraríamos que los productos renovables son fundamentales para invertir en la agronomía, este generaría más trabajo y aseguraría la alimentación y también el cuidado de la tierra, sin embargo, cada día la minería la contaminamos. Debemos ser más solidarios y preocuparnos por el otro. Al respecto Jonas (2014) en su libro sobre "el principio de una ética para la civilización tecnológica" muestra preocupación por el futuro de la humanidad, donde expresa la necesidad de mostrar humildad frente al poder transformador y vertiginoso que ocasiona la tecnociencia, así mismo señaló que el sujeto ético en una civilización tecnológica es de un rol responsable, precavido y cuidadoso, y el deber de preocuparnos por la búsqueda de vivir en un mundo lleno de virtud. (Trevisol, 2015).

\section{Discusión}

En 15 años siguientes las máquinas inteligentes reemplazaran a los maestros se escribió en Hacia la quinta revolución industrial (Vidal, 2019). Podemos preguntarnos ċlos algoritmos son capaces de ser educadores para los niños y estos verán una autoridad en los maestros robóticos?. Y crece la tensión donde las máquinas reemplazan al hombre. El Ministerio de Trabajo y Promoción del Empleo (2019) nos muestra que la realidad que sólo 24,708\% de trabajadores son formales y el $75 \%$ de trabajadores son informales. Además, existen brechas salariales entre hombres y mujeres de un 29\%. También hay trabajo infantil, encontramos 17\% de niños, niñas y adolescentes entre $(5 \mathrm{y}$ 13) en labores y adolescentes (14-17) son $8.5 \%$ de estos, según la encuesta del 2018. En esa línea Galanos (2019) analizó la preocupación del RE y la nueva forma de gobernanza en el nivel europeo, donde recomienda que los expertos en IA formulen políticas y exploración adicional de las redes de los individuos más prestigiosos y analizar los proyectos de las instituciones emergentes para hacer estudios de riesgos futuros.

Según Aliaga (2020) en nuestro país la "suspensión perfecta" o despidos masivos se dieron frente al contexto de la pandemia covid-19. Frente a ello surgió los contratos temporales, si esto ya es un hecho en nuestra realidad ¿porque no poner la alerta del riesgo laboral y la crisis que se está viviendo y la que vendrá? Los contratos laborales son precarios, temporales e inhumanos o hasta un despido anticipado encubierto. 
Al respecto Hans Jonás en el principio de la responsabilidad nos exhorta a combatir desde una ética de capacidad predictiva, no podemos esperar milagros tecnológicos que en el futuro mejoren la degradación de la naturaleza, para lo cual propone un cambio ético radical. Procurar la supervivencia de la humanidad descartando que la nueva tecnología lo resolverá todo. Por otro lado, vemos la inversión en proyectos millonarios para la nanotecnología que a su vez está logrando muchas cosas en el desarrollo y el progreso de sociedades, sin embargo, promete avances no muy asertivos para la humanidad como es la industria armamentista que dará lugar a las armas cibernéticas más sofisticadas que podría desatar una guerra nuclear, tales como armas manométricas, del tamaño de una molécula que serán más destructivas que las nucleares, químicas y biológicas. Ejemplo, un bolígrafo puede destruir toda una ciudad y cualquier país podría tener acceso las nanoarmas y cambiará las reglas de la disuasión y los actuales esquemas según el Comité Internacional de la Cruz Roja (2018) Esta tecnología está encabezada por Rusia y EEUU, es ya una carrera armamentista como afirma la BBC New (2016).

La religión y la tecnología han logrado comulgar en este siglo, la Iglesia Católica preocupada por los riesgos potenciales expresa su llamada de atención en "Rome Call for Ethics" o el llamado de una ética de la IA donde ha congregado empresarios, como John Kelly de IBM, así como representantes del parlamento europeo y la FAO para firmar un acuerdo de ética para la IA en Europa un acuerdo promovido por la Academia Pontificia por la Vida y que fue bendecido incluso por Papa Francisco. (Mundo, 2020). La humanidad necesita más comprensión y solidaridad del otro; pensar en el otro es reflejarnos a nosotros mismos y comprendernos (Gadamer; citado en Vergara, 2008). En el nuevo contexto del "liberalismo" ya lo decía Dewey y Keynes, la ciencia de las políticas públicas evolucionó rápidamente después de la segunda guerra mundial apareció como la ciencia de la administración del estado frente a lo público. Para lo cual se ha considerado el enfoque económico del comportamiento humano, Bentham señaló desde su perspectiva el cálculo del dolor y el placer ya está inmerso en todos los seres humanos, tales como las sanciones penales, las leyes sobre la usura, la jurisprudencia, así como los mercados de servicio y bienes. Los empresarios políticos, no razonan por los intereses del bien común porque la vieja teoría política buscaba el equilibrio plural, sin embargo, esta economía neoliberal es individualista. Olson, decía que los individuos tienen distintos intereses y por ello la sociedad está dividida en grupos. Al respecto Bentham (2003) refirió que iban a existir coaliciones mayoritarias frente a la minoría con intereses perversos y esto es adverso, para Mill es la mediocridad de la sociedad de masas. Hoy vemos como los medios de comunicación aliados con el gobierno mantienen desinformados a la población (Colomer, 2012).

Bentham y Smill (2003) señalaron que el hombre se rige por sus propios intereses y esto a su vez le lleva a buscar el placer y el dolor y si está en cada individuo rige para toda sociedad, así que el principio del interés está regido también para el principio de la felicidad. Esta teoría no niega que existan otras cosas por encima de la felicidad que también sean buenas. Sin embargo, lo único que no admite que lo distinto a la felicidad colectiva sea un bien en 
sí mismo. Esta teoría es considerada también como un sistema ético y por lo tanto admite a la bondad, la abnegación y el sacrificio. Niega en sus postulados el carácter de bondad intrínseca porque deben existir acciones valiosas por su intencionalidad. Mill consideró inútil un sacrificio que no aumente la felicidad. Por otro lado, Bentham aseguró que la felicidad pública debe ser el objeto de todo gobernador y la utilidad debe ser el principio que debe regir en el razonamiento del legislador, es decir ver siempre el bien de la comunidad.

\section{Conclusiones}

Es importante considerar como prioritario a la IA como un RE frente al futuro de la empleabilidad, se debe generar políticas públicas desde un análisis integrador e interdisciplinario y en articulación con otras instituciones tanto privadas como públicas. El avance de la tecnología, la ciencia y la IA han traído desarrollo, avances en educación, salud, empresas e instituciones y otros; sin embargo, por otro lado, también hay que evaluar el potencial riesgo que ocasionará a los trabajadores en la actualidad. Se debe reflexionar desde una política pública que considere en riego existencial el futuro de la empleabilidad frente al contexto covid-19 y pos-pandemia.

La IA rebasará la empleabilidad y debemos estar preparados porque ya estamos conviviendo con ellos, un chatbot, una máquina inteligente, y hasta un robot, son menos costosos que los propios humanos, y si son utilizados en sentido negativo alterará al hombre y hasta su condición de vida. Así como el mal uso que se viene dando a los dispositivos inteligentes cuando caiga en manos de mentes perversas y ambiciosas la humanidad estará en graves riesgos por eso es necesario pensar con ética y actuar pensando en el bien común.

\section{REFERENCIAS BIBLIOGRÁFICAS}

Aliaga, B. (19 de mayo del 2020). Diferencias prácticas en la aplicación de la suspensión perfecta de la LPCL y el DU 038-2020 y su impacto en los contratos temporales en tiempos del covid-19. Recuperado de https:// lpderecho.pe/diferencias-aplicacionsuspension-perfecta-Ipcl-du-038-2020/

Avalos, A., Haza, A. y Morales, P. (2016). Nanotecnología en la industria alimentaria II: evaluación del riesgo y legislación. Revista Complutense de Ciencias, 10 (2)

Arana, (2005). La Educación científicotecnológica desde los estudios de ciencia, ecnología, sociedad e innovación 3, 293 - 3131 Recuperado de https://www.redalyc.org/ pdf/396/39600315.pdf

BBC New (16 de febrero 2016). ¿Cuáles son las mayores amenazas que pueden acabar con la humanidad? Simon Beard $y$ Lauren Holt del Centro de Estudios de Riesgo Existencial. Recuperado de https://www. bbc.com/mundo/noticias-47253424

Beck, U. (2007). La sociedad del riesgo mundial en busca de la seguridad perdida. Barcelona: Paidós

Berdishewsky, B. (2002). Antropología social Introducción una visión global de la humanidad. Chile. LOM

Bernal, C. (2016). Metodología de la investigación. Colombia: Pearson 
Bentham, Smill (2003). The classical utililitarians. Edited, with Introduction, by John troyer. United Sates of America: Hackett Publishing Company

Bocanegra, E. (2015). Capacidad de respuesta del Estado en la Pandemia Perú: crisis, desafíos y entorno cambiante. Revista de Ciencia Política y Gobierno, 2 (4) 11-22

Bonilla, E. y Rodríguez, S. (2005). Más alla del dilema de los métodos: la investigación en ciencias sociales. Bogotá: Norma

Bostrom, N. (2014). Superintelligence: Paths, Dangers, Strategies, Orford, United Kingdom: Orford University Press

Brosi, Dodds, E Passeron (2019). Inteligencia artificial y bienestar de las juventudes en América Latina. Santiago de Chile: Concha y Toro ISBN: 978-95600-1237-1

Comisiòn Económica para América Latina y el Caribe (2020). FAO Y CEPAL: Millones de personas pueden caer en la pobreza extrema y el hambre en 2020 en América Latina y el Caribe debido al impacto de la pandemia. Naciones Unidad CEPAL

Comité Internacional de la Cruz Roja (7 de agosto del 2018). El arma más aterradora que se haya creado. Recuperado de https://www.icrc.org/es/document/ armas-nucleares-una-amenazaintolerable-para-la-humanidad

Cortina, A. (2008). Ética. Madrid. España: AKAL SA

De Siqueira, J. (2001). El principio de responsabilidad de Hans Jonas. Acta Bioethica, 7 Recuperado de https://scielo.conicyt.cl/scielo. php?script $=$ sci_arttext $\mathrm{spid}=\mathrm{S} 1726$ 569X2001000200009

Escolano, F., Cazorla, M. Galipienso, M, Colomina, O. y Lozano, M. (2003). Inteligencia Artificial, modleos, técnicas y áreas de aplicación. España: Paraninfo SA.

Galanos (2019). Exploring expanding expertise: artificial intelligence as existencial threat and the role of prestigious commentators (2014-2018)

Galeano, M. (2004). Diseño de proyectos en la investigación cualitativa. Colombia: Fondo Editorial Universidad EAFIT

García, L. (2019). La concepción del trabajo en la doctrina social de la iglesia católica: aportes y perspectivas relevantes para el derecho del trabajo. Círculo de Estudios laborales y Seguridad Social

Gestión (12 de diciembre del 2019). Inteligencia artificial robots podrían crear tantos trabajos como los que desplazan. Perú: Diario Gestión

Gestión (6 de mayo del 2020). Más de 200, 000 trabajadores fueron afectados por la suspensión perfecta de labores, según el MTPE. Perú: Diario Gestión

Gòmez, J. (2019). La inteligencia artificial y el futuro del trabajo. Lima. Perú: Diario El Peruano

Hulmes, D., (2017). Entrevista Riesgos existenciales y el destino humano al Astrònomo Martìn Rees. Recuperado de https://www.vision.org/es/node/6594

Jonas, J. (2014). El principio de responsabilidad, ensayo de una ética para la civilización tecnológica. Introducción de Andrés 
Sánchez Pascual. Barcelona. España: Herder

Martínez, R. y Reyes, E. (2012). EL Conceso de Washington: la instauración de las políticas neoliberales e América Latina. Scielo Politica y Cultura, primavera $3735-64$

Ministerio de Trabajo y Promoción del Empleo (2019). Acceso al empleo Pleno, Digno y Productivo. Ministerio de Trabajo

Mundo, (10 de marzo del 2020). Firman Acuerdo de ética para la Inteligencia Artificial e Europa. Recuperado de https://folou.co/mundo/acuerdointeligencia-artificial/

Organizaciòn Internacional del Trabajo (2002). El empleo, la empleabilidad y la igualdad de oportunidades en los servicios de correos y telecomunicaciones. Ginebra

Organización Mundial de la Salud OMS (1999). Plan de preparación ante la pandemia de influenza. Planificando el futuro. OMS

Organización de las Naciones Unidas para la Alimentación y la Agricultura (2017). Hacia el hambre cero 1945-2030: FAO
Rees, M. (24 de mayo 2019). Martìn Rees: "Por primera vez, un pequeño grupo $d$ epersonas puede destruir la humanidad. España (El Mundo)

Romero, S. (2019). Mètodo Mayeutica y consultorías filosóficas en el siglo XXI. PHAINOMENON 18 (2) 141-154

Subirat, J. (2008). Análisis y gestión de políticas públicas. España: Ariel SA.

Trevisol, M. (2015). EL sujeto en la civilización tecnológica. La propuesta de Hans Jonas. Universitas Philosphica 31, (63) DOI: 10.11144

Vergara, F. (2008). Gadamer y la comprensión efectual: Diálogo y tradición en el horizonte de la Koinè contemporánea. Revista Universum 23, 2 184-200

Zamorano, E. (26 de noviembre del 2012). Abren en Cambridge el "Centro para el estudio de Riesgos Existenciales.

Vidal, M. (2019). La era de la humanidad hacia la quinta revolución industrial. Deusto

Fecha de recepción: 10-03-2020

Fecha de aceptación: 05-04-2020 